\title{
Effects of hyperbaric oxygen on graft survival outcomes in composite grafting for amputated fingertip injury
}

\author{
Yoonsuk Lee ${ }^{1}$, Jae Won $\mathrm{Heo}^{2}$, Jin Sil Moon ${ }^{3}$, Sug Won Kim², Jiye Kim² \\ Departments of ${ }^{1}$ Emergency Medicine, ${ }^{2}$ Plastic and Reconstructive Surgery, and ${ }^{3}$ Biostatistics, Yonsei University Wonju College of Medicine, \\ Wonju, Korea
}

Background Fingertip injuries are the most common type of traumatic injury treated at emergency departments and require prompt and adequate interventions for favorable wound survival outcomes. Hyperbaric oxygen $\left(\mathrm{HBO}_{2}\right)$ therapy is well known for its many positive effects on wound healing. We hypothesized that treatment with $\mathrm{HBO}_{2}$ would improve the graft survival outcomes of amputated fingertip injuries treated with composite grafts.

Methods This retrospective observational study included fingertip amputations that were treated between January 2013 and December 2017. A conventional group and an $\mathrm{HBO}_{2}$ therapy group were statistically compared to evaluate the effect of $\mathrm{HBO}_{2}$ treatment. Graft survival was categorized as either success or failure.

Results Among 55 cases (digits), 34 digits were conventionally treated, while 21 digits were treated with $\mathrm{HBO}_{2}$. No statistically significant differences were observed between the groups with regard to general characteristics. Among patients with guillotine-type injuries, the composite graft success rate was statistically significantly higher in the group that received $\mathrm{HBO}_{2}$ therapy than in the conventional group $(\mathrm{P}=0.0337)$. Overall, the $\mathrm{HBO}_{2}$ group also demonstrated a statistically significantly shorter healing time than the conventional group $(P=0.0075)$. As such, $\mathrm{HBO}_{2}$ treatment facilitates composite graft survival in cases of fingertip injury.

Conclusions $\mathrm{HBO}_{2}$ treatment was associated with an increased composite graft survival rate in guillotine-type fingertip injuries and reduced the time required for grafts to heal.

Keywords Composite tissue allografts / Amputation / Hyperbaric oxygen therapy
Correspondence: Jiye Kim Department of Plastic and Reconstructive Surgery, Yonsei University Wonju College of Medicine, 20 Ilsan-ro, Wonju 26426, Korea Tel: $+82-33-741-0611$

Fax: +82-33-732-4022

E-mail: gen80@yonsei.ac.kr

This study was supported by a grant from the Korea Health Technology R\&D Project through the Korea Health Industry Development Institute, funded by the Ministry of Health and Welfare of the Republic of Korea (grant number: HI18C2196).

Received: March 13, $2020 \bullet$ Revised: July 2, 2020 - Accepted: July 15, 2020

pISSN: 2234-6163 • elSSN: 2234-6171 • https://doi.org/10.5999/aps.2020.00381 • Arch Plast Surg 2020;47:444-450

\section{INTRODUCTION}

Among the various traumatic injuries treated at emergency departments, fingertip injuries are the most common and require prompt and adequate intervention for favorable outcomes [1]. We defined the fingertip as the portion of the digit distal to the insertion of the flexor and extensor tendons on the distal phalanx [2]. For amputated fingertip injuries, microsurgical replantation of the amputated fingertip to the stump is needed to achieve satisfactory recovery with regard to the length and function of the injured finger [3]. However, microanastomosis of the fingertip amputation distal to the germinal matrix of the nail is 
difficult and requires an experienced microsurgeon. In cases of crush injury in particular, the injured vessels of the fingertip are not suitable for microanastomosis $[4,5]$. Without early microanastomosis, the expected outcome is not favorable. Therefore, a composite graft with the distal stump can be a treatment option. Composite grafting of the fingertip is affected by plasma imbibition and vascular inosculation through the cut edges, and its success rate is associated with delicate surgical procedures and postoperative care [6]. To improve the survival outcomes of composite grafts, many adjuvant methods can be used [7-11]. Hyperbaric oxygen $\left(\mathrm{HBO}_{2}\right)$ therapy is well known for its many positive effects on wound healing [12]. Previous animal studies have shown that the application of $\mathrm{HBO}_{2}$ to composite grafts in rats and rabbits increased graft survival $[13,14]$. Systemic $\mathrm{HBO}_{2}$ treatment increases oxygen diffusion, improves the condition of ischemia-reperfusion injuries, and stimulates angiogenesis [12]. For compromised flaps and grafts, $\mathrm{HBO}_{2}$ is typically applied at 2.0-2.5 atmospheres absolute (ATA) for 90- to 120-minute periods twice daily [15]. For split-thickness skin grafts, the application of $\mathrm{HBO}_{2}$ before and after surgery can improve the survival rate [16]. Many trials have been designed to verify the effect of hyperbaric therapy on composite grafts in animal studies. However, few clinical comparison studies have been conducted to analyze the effect of systemic $\mathrm{HBO}_{2}$ on composite grafts in humans. This study was conducted to evaluate the effect of systemic $\mathrm{HBO}_{2}$ on composite graft survival in cases of amputated fingertip injury.

\section{METHODS}

\section{Study design and setting}

In this retrospective observational study, we reviewed patients of all ages who were treated between January 2013 and December 2017 with composite grafting for fingertip amputations distal to the germinal matrix with microsurgically non-replantable distal amputated fingertips. We identified 55 consecutive patients with amputated fingertips who were admitted for surgical repair and adjunct treatments. The $\mathrm{HBO}_{2}$ therapy center in Korea is newly established [17]. Our institution opened this center with one multiplace chamber, in which six patients can be treated in one session, in October 2015. Patients treated prior to October 2015 received conventional adjunct treatments only, and consenting patients treated after the opening of the center received $\mathrm{HBO}_{2}$ in addition to the conventional adjunct therapies.

Electronic medical records, X-ray films, clinical photographs of the wounds, and demographic information were reviewed and recorded. We collected information regarding patient age, sex, medical history of hypertension and diabetes, smoking his- tory, the specific digit involved, the level of the injury (or Allen classification), the geometry and mechanism of the injury, the time to surgery, the time from the injury to the first $\mathrm{HBO}_{2}$ treatment, the total number of $\mathrm{HBO}_{2}$ treatment sessions, and the healing time. The outcome analysis included only injuries with Allen classifications of types I, II, and III, the last of which involves distal phalanx fracture [18]. We categorized the mechanism of injury into either guillotine (clean-cut) or crush injury. A third subcategory, sawing injury, was represented as well, but we excluded it from the outcome analysis due to the small number of cases. We classified the geometry of the injury into four subgroups: dorsal oblique, volar oblique, lateral oblique, and transverse [7].

This study protocol was approved by the Institutional Review Board of Wonju Severance Christian Hospital (IRB No. CR319010). Since this study was retrospective and observational, patient records and information were anonymously collected prior to analysis. Thus, the requirement for informed consent was waived.

\section{Surgical management}

When a patient visited the emergency department, an emergency physician evaluated the wound and properly irrigated the area, then notified a board-certified plastic and reconstructive surgeon who had completed a hand surgery fellowship. The same surgical technique was used for all patients. Before the procedure, the surgeon evaluated all amputations under a microscope or loupe to plan for microanastomosis. All amputated parts and digital stumps were cleaned and debrided under general anesthetic or brachial plexus/digital block. Under the microscope or loupe, debris and devitalized tissue were removed before composite grafting. Bleeding was meticulously controlled, after which the composite graft was placed using the amputated tip and sutured with 5-0 nylon sutures. The margin of the composite graft was accurately sutured with a simple or vertical mattress suture under loupe magnification. If the nail plate was present, it was temporarily removed to allow nail bed repair. After nail bed repair, the whole nail was placed back into the nail fold and sutured with 4-0 nylon.

\section{Postoperative management}

All patients were admitted for 7 days from the completion of the composite graft and treated with intravenous empirical antibiotics and prostaglandin E (alprostadil alpha-cyclodextrin). No ice was applied for cooling after the composite graft. The reattached fingertip was treated with antibiotic ointment (oxytetracycline hydrochloride and polymyxin B sulfate) and, in a non-traumatic procedure, was wrapped in non-adherent hydrocolloid dressing 


\section{Fig. 1. Application of the $\mathrm{HBO}_{2}$ protocol}

The hyperbaric oxygen $\left(\mathrm{HBO}_{2}\right)$ treatment was applied with initial compression to 2.8 atmospheres absolute (ATA) and $100 \% \mathrm{O}_{2}$ administered for 45 minutes. After 45 minutes at 2.8 ATA, injuries were decompressed to 2.0 ATA within 5 minutes and given a 5-minute air break (no oxygen). After the air break, patients were treated at 2.0 ATA for 55 minutes, after which the protocol was terminated. PT, patient; OPT, optional.

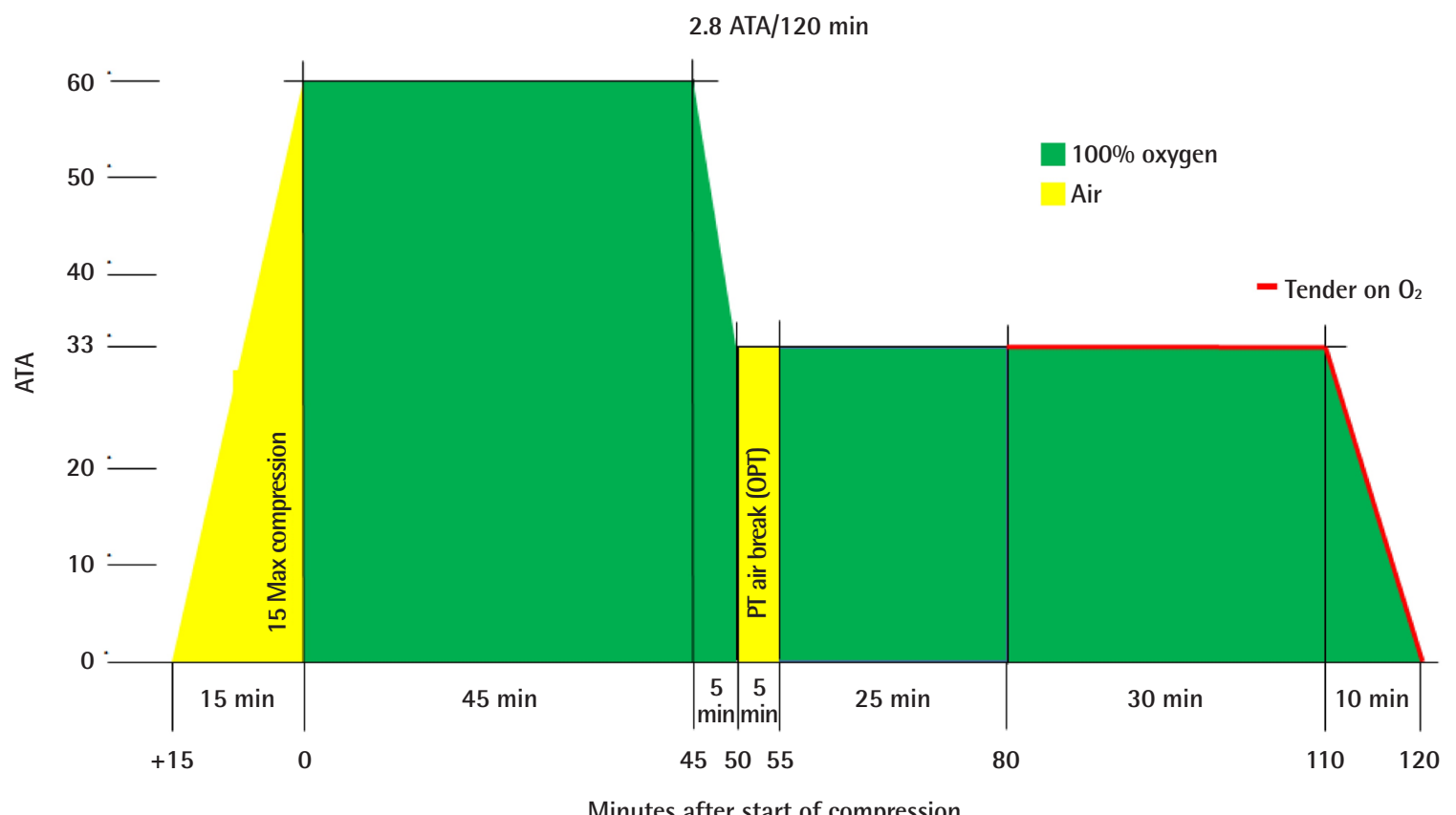

(Physiotulle; Coloplast, Peterborough, UK) to maintain a moist environment. For patients in the $\mathrm{HBO}_{2}$ group, the treatment was applied as soon as possible after surgery, with initial compression to 2.8 ATA and $100 \% \mathrm{O}_{2}$ applied for 45 minutes. After 45 minutes at 2.8 ATA, the injuries were decompressed to 2.0 ATA within 5 minutes and given a 5-minute air break (no oxygen). After the air break, patients were treated at 2.0 ATA for 55 minutes, after which the protocol was terminated (Fig. 1).

\section{Definition of the outcome}

After composite grafting, the surgeon assessed the outcomes over the course of 8 weeks. In each case, the outcome was categorized as either success or failure. A graft was defined as successful if it completely healed within 8 weeks (Fig. 2), while failure was defined as a lack of complete healing over that time period (Fig. 3). We also classified cases that could not be healed with secondary intention and required additional procedures, such as stump revision and flap surgery, as failure. We described the healing time as the time (in weeks) required for graft survival after surgery.

\section{Statistical analysis}

A biomedical statistician analyzed the collected data. Proper sta- tistical methods were determined according to the properties of the variables. Categorical variables were statistically analyzed using the chi-square test and the Fisher exact test, while continuous variables were statistically analyzed using the two-sample ttest. Since the normality assumption did not apply to healing time, a non-parametric test (the Wilcoxon signed-rank test) was used. A P-value of < 0.05 was considered to indicate statistical significance. SAS 9.4 software (SAS Institute Inc., Cary, NC, USA) was used for the statistical analyses in this study.

\section{RESULTS}

\section{Descriptive statistics for the two groups}

Among the 55 digits that we reviewed, 34 digits were conventionally treated, while 21 digits were treated with $\mathrm{HBO}_{2}$ (Table 1 ). The two groups had no statistically significant differences with regard to age, sex, hypertension, diabetes, or smoking history. The Allen classification and mean time to surgery similarly showed no significant differences between groups (Table 2). Fingertip injuries of the left hand were more frequent than those of the right side. The most frequently injured finger was the third (middle) finger in the conventional group and the second (index) finger in the $\mathrm{HBO}_{2}$ group. Regarding the injury geome- 


\section{Fig. 2. Example of success}

(A) Preoperative photo of a patient who was injured in a lateral oblique pattern. (B) Immediate postoperative photo; a pale color was observed. (C) Two weeks after the operation, the fingertip had recovered to gain a pinkish color after revascularization was completed.
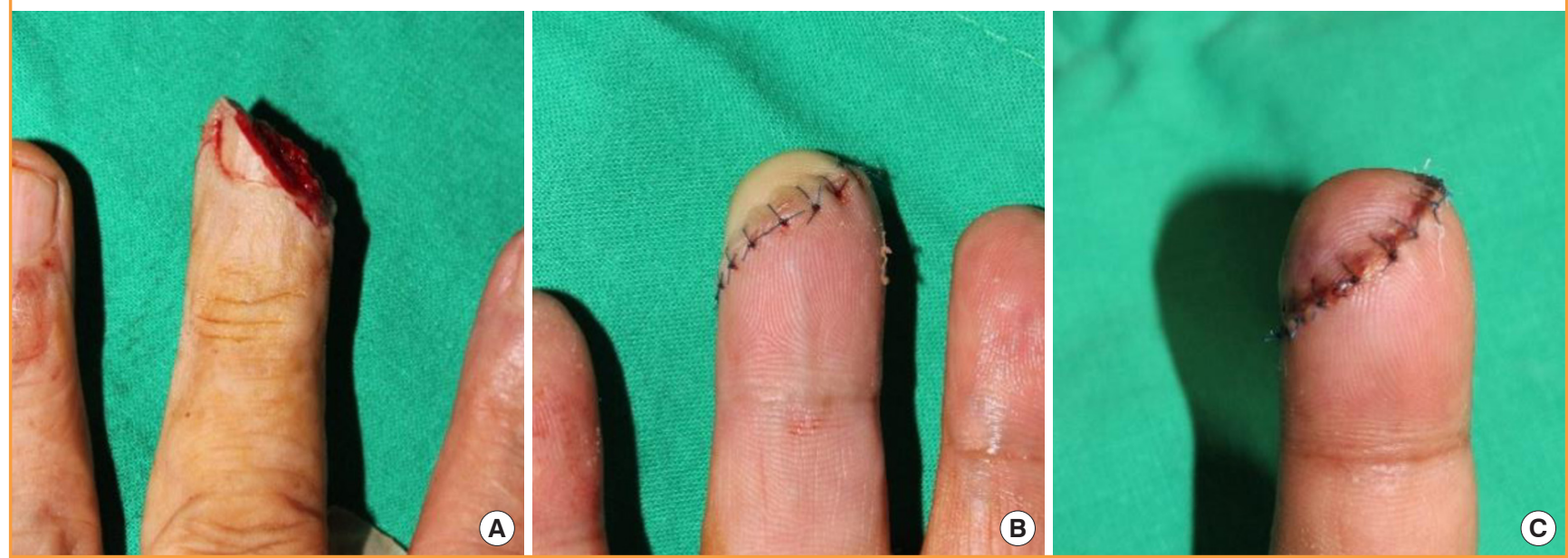

\section{Fig. 3. Example of failure}

(A) Preoperative photo of a patient who was injured in a volar pattern. (B) Immediate postoperative photo; a pale color was observed, and the distal phalangeal bone fracture was fixed with K-wire. (C) Two weeks after the operation, total necrosis was observed. This case was judged as graft failure, as it required additional procedure(s) such as debridement.
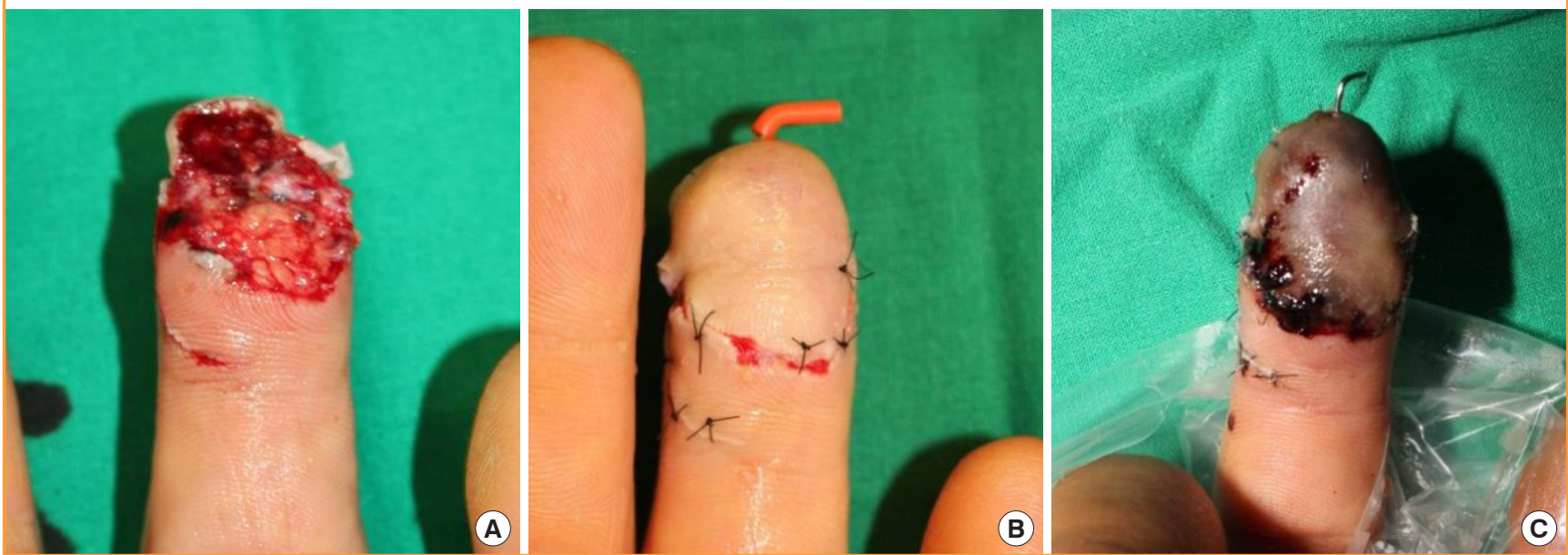

try and mechanism, in both groups, volar oblique injuries were prevalent, and guillotine injuries were more frequent than crush injuries. The mean time from injury to composite graft was 3.46 hours in the conventional group and 4.12 hours in the $\mathrm{HBO}_{2}$ group, but this difference was not statistically significant.

\section{Composite graft outcome analysis}

The graft success rate was higher in the $\mathrm{HBO}_{2}$ group (57.1\%) than in the conventional group (47.1\%). However, no statistically significant difference was observed with regard to the overall graft success outcomes (Table 1). We analyzed the graft outcomes according to the mechanism of injury. Guillotine injuries were associated with a statistically significantly higher rate of success in the $\mathrm{HBO}_{2}$ group than in the conventional group $(\mathrm{P}=$ 0.0337), while crush injuries showed poor results in both groups (Table 3). Overall, within the $\mathrm{HBO}_{2}$ group, the time from injury to the first $\mathrm{HBO}_{2}$ treatment received and the total number of $\mathrm{HBO}_{2}$ sessions were not found to be statistically related to the outcome (Table 4).

\section{Healing time analysis}

The $\mathrm{HBO}_{2}$ group had a shorter healing time than the conventional group, with median healing times of 3 weeks (range, 2-5 weeks) and 4 weeks (range, 3-7 weeks), respectively; this difference was statistically significant $(\mathrm{P}=0.0075)$ (Table 5). 
Table 1. Baseline characteristics of the conventional and $\mathrm{HBO}_{2}$ groups

\begin{tabular}{|c|c|c|c|}
\hline Variable & $\begin{array}{c}\text { Conventional } \\
(n=34)\end{array}$ & $\begin{array}{c}\mathrm{HBO}_{2} \\
(\mathrm{n}=21)\end{array}$ & P-value \\
\hline Age (yr) & $42.62 \pm 14.29$ & $44.81 \pm 17.00$ & 0.6095 \\
\hline Sex & & & 0.5608 \\
\hline Male & $14(41.18)$ & 7 (33.33) & \\
\hline Female & $20(58.82)$ & $14(66.67)$ & \\
\hline Hypertension & & & $0.2361^{\text {a) }}$ \\
\hline No & 31 (91.18) & $16(76.19)$ & \\
\hline Yes & $3(8.82)$ & $5(23.81)$ & \\
\hline Diabetes mellitus & & & 1.0000 \\
\hline No & 33 (97.06) & $21(100.00)$ & \\
\hline Yes & $1(2.94)$ & 0 & \\
\hline Smoking & & & 0.7866 \\
\hline Non-smoker & $24(70.59)$ & $13(61.90)$ & \\
\hline Current smoker & $9(26.47)$ & 7 (33.33) & \\
\hline Ex-smoker & $1(2.94)$ & $1(4.76)$ & \\
\hline Pack-years & & & $0.7020^{\mathrm{a})}$ \\
\hline 0 & 24 (70.59) & $13(61.90)$ & \\
\hline $1-5$ & $1(2.94)$ & 0 & \\
\hline $6-10$ & $2(5.88)$ & 4 (19.05) & \\
\hline $11-20$ & $3(8.82)$ & $2(9.52)$ & \\
\hline $21-30$ & $3(8.82)$ & $2(9.52)$ & \\
\hline $31-40$ & $1(2.94)$ & 0 & \\
\hline Mechanism of injury & & & $0.0529^{\mathrm{a})}$ \\
\hline Guillotine & $24(70.59)$ & $10(47.62)$ & \\
\hline Crush & $10(29.41)$ & $8(38.10)$ & \\
\hline Sawing & 0 & $3(14.29)$ & \\
\hline Hand & & & 0.2083 \\
\hline Left & $25(73.53)$ & $12(57.14)$ & \\
\hline Right & $9(26.47)$ & $9(42.86)$ & \\
\hline Finger & & & $0.1949^{\mathrm{a})}$ \\
\hline First & $6(17.65)$ & $6(28.57)$ & \\
\hline Second & $11(32.35)$ & $9(42.86)$ & \\
\hline Third & $12(35.29)$ & $2(9.52)$ & \\
\hline Fourth & $3(8.82)$ & $1(4.76)$ & \\
\hline Fifth & $2(5.88)$ & $3(14.29)$ & \\
\hline Geometry of injury & & & $0.6214^{a)}$ \\
\hline Volar & $11(32.35)$ & 7 (33.33) & \\
\hline Dorsal oblique & $5(14.71)$ & 4 (19.05) & \\
\hline Transverse & 8 (23.53) & 7 (33.33) & \\
\hline Lateral oblique & $10(29.41)$ & $3(14.29)$ & \\
\hline Allen classification & & & $0.0903^{\mathrm{a})}$ \\
\hline I & $14(41.18)$ & 7 (33.33) & \\
\hline$\|$ & $18(52.94)$ & $8(38.10)$ & \\
\hline III & $2(5.88)$ & $6(28.57)$ & \\
\hline Mean time to surgery (hr) & $3.46 \pm 1.58$ & $4.12 \pm 2.60$ & 0.3062 \\
\hline Outcome & & & 0.4674 \\
\hline Success & $16(47.06)$ & $12(57.14)$ & \\
\hline Failure & $18(52.94)$ & $9(42.86)$ & \\
\hline \multicolumn{4}{|c|}{$\begin{array}{l}\text { Values are presented as mean } \pm \mathrm{SD} \text { or number (\%). } \\
\mathrm{HBO}_{2} \text {, hyperbaric oxygen. } \\
\text { a) Fisher exact test. }\end{array}$} \\
\hline
\end{tabular}

\section{DISCUSSION}

In this study, we evaluated the clinical effect of $\mathrm{HBO}_{2}$ therapy on composite graft survival in cases of fingertip injury. Fifty-five
Table 2. Graft outcomes by age, smoking status, hypertension, diabetes, and Allen classification

\begin{tabular}{|c|c|c|c|}
\hline Variable & $\begin{array}{l}\text { Failure } \\
(n=27)\end{array}$ & $\begin{array}{l}\text { Success } \\
(n=28)\end{array}$ & P-value \\
\hline Age (yr) & $46.07 \pm 18.00$ & $40.93 \pm 11.84$ & 0.2187 \\
\hline Smoking status & & & 0.6802 \\
\hline Non-smoker & $20(54.05)$ & $17(45.95)$ & \\
\hline Current smoker & $6(37.50)$ & $10(62.50)$ & \\
\hline Ex-smoker & $1(50.00)$ & $1(50.00)$ & \\
\hline Hypertension & & & 0.1430 \\
\hline No & 21 (44.68) & 26 (55.32) & \\
\hline Yes & $6(22.22)$ & $2(7.14)$ & \\
\hline Diabetes mellitus & & & 1.0000 \\
\hline No & 27 (50.00) & 27 (50.00) & \\
\hline Yes & 0 & $1(100.00)$ & \\
\hline Allen classification & & & 0.6651 \\
\hline I & $9(42.86)$ & $12(57.14)$ & \\
\hline$\|$ & $13(50.00)$ & $13(50.00)$ & \\
\hline III & $5(62.50)$ & $3(37.50)$ & \\
\hline
\end{tabular}

fingertip injuries treated with composite grafting were included in the analysis. These composite graft cases included 28 cases of graft success (50.9\%) and 27 cases of failure (49.1\%). Age, sex, hypertension, diabetes mellitus, smoking history, the mechanism of the injury, and the geometry of the injury were reviewed as baseline characteristics. The conventional and $\mathrm{HBO}_{2}$ groups showed no statistically significant differences in these baseline characteristics.

$\mathrm{HBO}_{2}$ treatment involves the administration of a high concentration of oxygen in a high-pressure environment, with the patient breathing $100 \%$ oxygen at a pressure of 1.4 atmospheres or higher [19]. $\mathrm{HBO}_{2}$ can be applied at pressures of 2.0-3.0 ATA for periods of 1 to 4 hours. The arterial $\mathrm{PO}_{2}$ becomes elevated to $1,000-1,500 \mathrm{mmHg}$ due to dissolved oxygen in the plasma. At the tissue and cellular levels, hyperoxygenation promotes angiogenesis and improves post-ischemic tissue survival. Increasing the applied pressure increases the $\mathrm{PO}_{2}$ of the tissue, which is beneficial for wound healing [20].

Most oxygen transported through the blood is carried in the form of oxyhemoglobin; specifically, $20 \mathrm{~mL}$ of oxygen is attached to hemoglobin per $100 \mathrm{~mL}$ of blood at standard atmospheric pressure. In contrast, only $0.3 \mathrm{~mL}$ of oxygen is dissolved in the plasma per $100 \mathrm{~mL}$ of blood. If the atmospheric pressure is raised to 3.0 atmospheres, the partial pressure of arterial oxygen reaches $2,200 \mathrm{mmHg}$. The dissolved plasma oxygen level increases from $0.3 \mathrm{~mL}$ to $5.4 \mathrm{~mL}$, which is about 18 times the level at standard atmospheric pressure. This elevated partial pressure of oxygen can provide enough oxygen to maintain basal metabolic function without normal hemoglobin, which is the principle of $\mathrm{HBO}_{2}$ treatment [12]. 
Table 3. Graft outcomes in conventional and $\mathrm{HBO}_{2}$ groups by type of injury (guillotine or crush)

\begin{tabular}{|c|c|c|c|c|c|c|c|c|}
\hline \multirow{2}{*}{ Outcome } & \multicolumn{4}{|c|}{ Guillotine $(n=34)$} & \multicolumn{4}{|c|}{ Crush $(n=18)^{a)}$} \\
\hline & Total & Conventional & $\mathrm{HBO}_{2}$ & P-value & Total & Conventional & $\mathrm{HBO}_{2}$ & P-value \\
\hline Success & $25(73.53)$ & $15(62.50)$ & $10(100.00)$ & 0.0337 & $2(11.11)$ & $1(10.00)$ & $1(12.50)$ & 1.0000 \\
\hline Failure & $9(26.47)$ & $9(37.50)$ & 0 & & $16(88.89)$ & $9(90.00)$ & $7(87.50)$ & \\
\hline
\end{tabular}

Table 4. Graft outcomes by total number of $\mathrm{HBO}_{2}$ sessions and time from injury to $\mathrm{HBO}_{2}$ treatment

\begin{tabular}{|llccc|}
\hline Outcome & $\begin{array}{c}\text { From injury } \\
\text { to } \mathrm{HBO}_{2}(\mathrm{hr})\end{array}$ & P-value & $\begin{array}{c}\mathrm{Total}_{\mathrm{HBO}} \\
\text { count }\end{array}$ & P-value \\
\hline Success & $33.30 \pm 17.43$ & 0.7840 & $8.25 \pm 3.60$ & 0.4961 \\
Failure & $37.72 \pm 44.59$ & & $9.22 \pm 2.49$ & \\
\hline $\begin{array}{l}\text { Values are presented as mean } \pm \mathrm{SD} . \\
\mathrm{HBO}_{2} \text {, hyperbaric oxygen. }\end{array}$ & & \\
\hline
\end{tabular}

In addition to hyperoxygenation, as a secondary mechanism, $\mathrm{HBO}_{2}$ promotes tissue regeneration and neovascularization in skin grafts and flaps [16]. The effect of $\mathrm{HBO}_{2}$ on skin grafts and flaps is thought to improve wound oxygen tension, fibroblast function (collagen synthesis), and vascularization [15]. Large amounts of animal data and multiple serials of clinical case reports have been published regarding the effectiveness of $\mathrm{HBO}_{2}$ in skin grafts, composite grafts, and flap ischemia. Even though many studies have discussed the efficacy of $\mathrm{HBO}_{2}$ in grafts and flaps, comparative clinical studies of $\mathrm{HBO}_{2}$ are rare, as it is challenging to collect identical cases to compare. Evaluating the effect of $\mathrm{HBO}_{2}$ alone is also difficult due to the challenges associated with obtaining patient consent to observe the flap or graft without additional adjunct therapy.

Before conducting the data analysis, we hypothesized that $\mathrm{HBO}_{2}$ would be effective in the treatment of fingertip injury. We also expected that $\mathrm{HBO}_{2}$ treatment would be more beneficial for crush injuries than for guillotine injuries. Generally, the survival of a composite graft after a crush injury is more difficult to attain [21]. Thus, we compared the success rate according to $\mathrm{HBO}_{2}$ treatment status for guillotine and crush injuries. For both the conventional and $\mathrm{HBO}_{2}$ groups, guillotine injuries were associated with a significantly higher proportion of successful outcomes than crush injuries (Table 3). The results also showed that $\mathrm{HBO}_{2}$ treatment increased the graft survival rate in patients with guillotine-type fingertip injuries. However, in the crush injury group, $\mathrm{HBO}_{2}$ therapy did not significantly affect graft outcomes. Considering the mechanism by which $\mathrm{HBO}_{2}$ increases graft survival by promoting angiogenesis caused by hyperoxygenation, we hypothesized that the crushed amputation
Table 5. Median healing time in the conventional and $\mathrm{HBO}_{2}$ groups

\begin{tabular}{|c|c|c|c|}
\hline & Conventional & $\mathrm{HBO}_{2}$ & P-value \\
\hline Median in weeks (min, max) & $4(3,7)$ & $3(2,5)$ & 0.0075 \\
\hline
\end{tabular}

was unsuitable for angiogenesis or neovascularization. Therefore, crush fingertip injuries treated with composite grafts do not appear to be an appropriate indication for $\mathrm{HBO}_{2}$ treatment.

Another outcome that we considered was healing time. The $\mathrm{HBO}_{2}$ group showed a median healing time of 3 weeks, while the median healing period for the conventional group was 4 weeks. This difference in healing time was statistically significant, with a statistical power $(1-\beta)$ of $85.5 \%$. The shorter healing time in the $\mathrm{HBO}_{2}$ group could be related to faster restoration of the function of the injured finger and a reduction in the number of clinic visits.

This study had a few limitations. First, it was retrospective in nature. The outcomes were reviewed only through images and the descriptions in the electrical medical records. Some data were missing, and not all information on necessary parameters could be obtained. Second, the statistical analysis was limited. This study included only patients from a short period, and information was collected from a single center representing only one region. To overcome the limitation of the small sample size, we collected the data consecutively. Lastly, during the study period, we only had one multiplace chamber, so we could not differentiate the $\mathrm{HBO}_{2}$ treatment protocol by indication; rather, we had to apply a single treatment protocol for every patient. Differences in the applied pressure and the number of $\mathrm{HBO}_{2}$ treatments per day may affect the wound survival outcome. Future studies may be used to develop an optimal treatment protocol.

$\mathrm{HBO}_{2}$ treatment effectively facilitates composite graft survival in guillotine-type fingertip injuries. $\mathrm{HBO}_{2}$ can also decrease the time required for the composite graft to heal. $\mathrm{HBO}_{2}$ therapy appears to increase survival rate and improve healing time in fingertip injuries treated with composite grafting, and it is considered to be adequate to perform in cases of guillotine injury, 
where the cutting surface is relatively clean. However, the effect may not be significant in cases of crush injury, so we expect that additional adjuvant therapy or another reconstruction plan will be required. Additionally, future randomized controlled trials with adequate sample sizes may be needed.

\section{NOTES}

\section{Conflict of interest}

No potential conflict of interest relevant to this article was reported.

\section{Ethical approval}

The study was approved by the Institutional Review Board of Wonju Severance Christian Hospital (IRB No. CR319010) and performed in accordance with the principles of the Declaration of Helsinki.

\section{Patient consent}

The patients provided written informed consent for the publication and the use of their images.

\section{Author contribution}

Conceptualization: J Kim. Data curation: JS Moon. Formal analysis: JS Moon. Methodology: JW Heo. Writing - original draft: Y Lee, JW Heo. Writing - review \& editing: SW Kim.

\section{ORCID}

Yoonsuk Lee https://orcid.org/0000-0003-0404-7255 Jae Won Heo https://orcid.org/0000-0002-9070-5244 Jin Sil Moon https://orcid.org/0000-0002-6197-7742 Sug Won Kim https://orcid.org/0000-0002-2354-7100 Jiye Kim https://orcid.org/0000-0002-1724-4250

\section{REFERENCES}

1. Sorock GS, Lombardi DA, Hauser RB, et al. Acute traumatic occupational hand injuries: type, location, and severity. J Occup Environ Med 2002;44:345-51.

2. Fassler PR. Fingertip injuries: evaluation and treatment. J Am Acad Orthop Surg 1996;4:84-92.

3. Ryu DH, Roh SY, Kim JS, et al. Multiple venous anastomoses decrease the need for intensive postoperative management in tamai zone I replantations. Arch Plast Surg 2018;45: 58-61.

4. Chen SY, Wang CH, Fu JP, et al. Composite grafting for traumatic fingertip amputation in adults: technique reinforcement and experience in 31 digits. J Trauma 2011;70:148-53.
5. Koh SH, You Y, Kim YW, et al. Long-term outcomes of nail bed reconstruction. Arch Plast Surg 2019;46:580-8.

6. Raurell A, Ahmed O, George E, et al. V-Y advancement flap and composite graft for alar-groove reconstruction. $\mathrm{Br} \mathrm{J}$ Plast Surg 2002;55:8-11.

7. Hartman DF, Goode RL. Pharmacologic enhancement of composite graft survival. Arch Otolaryngol Head Neck Surg 1987;113:720-3.

8. Aden KK, Biel MA. The evaluation of pharmacologic agents on composite graft survival. Arch Otolaryngol Head Neck Surg 1992;118:175-8.

9. Fann PC, Hartman DF, Goode RL. Pharmacologic and surgical enhancement of composite graft survival. Arch Otolaryngol Head Neck Surg 1993;119:313-9.

10. Henrich DE, Logan TC, Lewis RS, et al. Composite graft survival: an auricular amputation model. Arch Otolaryngol Head Neck Surg 1995;121:1137-42.

11. Kadota H, Imaizumi A, Ishida K, et al. Successful local use of heparin calcium for congested fingertip replants. Arch Plast Surg 2020;47:54-61.

12. Thom SR. Hyperbaric oxygen: its mechanisms and efficacy. Plast Reconstr Surg 2011;127 Suppl 1:131S-141S.

13. Fodor L, Ramon Y, Meilik B, et al. Effect of hyperbaric oxygen on survival of composite grafts in rats. Scand J Plast Reconstr Surg Hand Surg 2006;40:257-60.

14. Li EN, Menon NG, Rodriguez ED, et al. The effect of hyperbaric oxygen therapy on composite graft survival. Ann Plast Surg 2004;53:141-5.

15. Francis A, Baynosa RC. Hyperbaric oxygen therapy for the compromised graft or flap. Adv Wound Care (New Rochelle) 2017;6:23-32.

16. Friedman HI, Fitzmaurice M, Lefaivre JF, et al. An evidencebased appraisal of the use of hyperbaric oxygen on flaps and grafts. Plast Reconstr Surg 2006;117(7 Suppl):175S-190S.

17. Kim YS, Lee Y, Kim SJ, et al. Operation of a hyperbaric oxygen therapy center in Korea: report of our experience from a setting in its nascent stages. Undersea Hyperb Med 2019;46: 135-43.

18. Lee DH, Mignemi ME, Crosby SN. Fingertip injuries: an update on management. J Am Acad Orthop Surg 2013;21:75666.

19. Vincent JL, Abraham E, Moore FA, et al. Textbook of critical care. 7th ed. Philadelphia: Elsevier; 2017.

20. Moon RE. Hyperbaric oxygen therapy indications. 14th ed. North Palm Beach: Best Publishing Company; 2019.

21. Sebastin SJ, Chung KC. A systematic review of the outcomes of replantation of distal digital amputation. Plast Reconstr Surg 2011;128:723-37. 